\title{
Demulsification of Crude Oil Emulsion in Well $X$ in a Niger Delta Field
}

\author{
Marian Charles Abatai ${ }^{*}$, Julius Udo Akpabio, Anietie Ndarake Okon, Benjamin Reuben Etuk
}

Department of Chemical and Petroleum Engineering, Faculty of Engineering, University of Uyo, Uyo, Nigeria

\author{
Email address: \\ mariancharles2020@icloud.com (M. C. Abatai) \\ ${ }^{*}$ Corresponding author
}

\section{To cite this article:}

Marian Charles Abatai, Julius Udo Akpabio, Anietie Ndarake Okon, Benjamin Reuben Etuk. Demulsification of Crude Oil Emulsion in Well $\mathrm{X}$ in a Niger Delta Field. Engineering and Applied Sciences. Vol. 5, No. 5, 2020, pp. 83-91. doi: 10.11648/j.eas.20200505.11

Received: September 3, 2020; Accepted: September 18, 2020; Published: September 28, 2020

\begin{abstract}
Crude oil emulsion is an inevitable phenomenon in hydrocarbon production. Treatment of crude oil emulsion is challenging when the emulsion is stabilized. As crude oil is brought to the surface and pumped to the production facilities, the formation of emulsion increases operating cost. There is a wide array of demulsifiers that are available in the oil and gas industry for the treatment of crude oil emulsion, but one major concern has always been the efficiency of the treatment. No single universal demulsifier can effectively remove emulsion and a combination of two or more is usually expensive. In this study, crude samples were collected from the inlet manifold of a Niger Delta field and bottle tests were conducted with several demulsifiers to select the best chemical demulsifier for use in treating the emulsions as well as the optimum combination. To achieve this objective, twelve different industrial-based demulsifiers were considered which were EXP50, Separol NF-36, Baker-Basf V13-312, Servo CC-8271, Tretolite RP6275, NACCO-Exxon 006-1442, DMO87005, EXP30, AnticorQIT007, AnticorBE027, DMO86634 and DMO81656. It was observed that DMO87005 and AnticorQIT007 produced better results based on separated water volume than other demulsifiers. Hence, the decision to use these demulsifiers to assess their combined potential and the demulsifier factors, namely, concentration, temperature and time effects on the separated water volume using design of experiments (DOE) approach. The results obtained shows that the selected demulsifiers DMO87005 and AnticorQIT007 in a combined form separate more water volume from the crude oil emulsion. Also, the performance of the combined demulsifier is dependent on the combination ratio of the selected demulsifiers. Furthermore, the results depict that the selected (non-combined) demulsifiers and the combined demulsifier factors' main effects on the separated water volume are concentration, while concentration-time and temperature-time are the factors' interaction effects for selected and combined demulsifiers, respectively. Again, the magnitude of the main and interaction effects of the combined demulsifier's factors on the separated water volume is affected by the selected demulsifiers combination ratio. Thus, the combined demulsifier at $0.45 \mathrm{~mL}$ concentration at a temperature of $90^{\circ} \mathrm{C}$ for 60 minutes gave a good potential that would necessitate its use for crude oil emulsion treatment in the Niger Delta.
\end{abstract}

Keywords: Crude Oil, Emulsion, Demulsifier, Design of Experiments, Niger Delta

\section{Introduction}

The most important objective of any oil production facility is the separation of water from produced crude [1]. Oil production is always accompanied by the undesired formation of emulsions due to the presence of naturally occurring surface-active molecules such as asphaltenes and resins [1]. Thus, the mixture of oil and water during production activity is known as emulsion. They are actually defined as a suspension of droplets, greater than 0.1 micron in diameter, consisting of two completely immiscible liquids, one of which is dispersed throughout the other [2].

The presence of emulsifier stabilizes the oil/water interface and therefore, it is necessary to break the emulsions by adding other surface-active molecules like fatty acids sulfonates, ethoxylated compounds such as ethoxylated propylene glycol. The quick and efficient breaking of emulsions is essential to meet downstream crude oil specifications. In general, crude oil is produced as water in oil emulsion and demulsifiers are necessary to break such emulsions. Demulsifiers (or emulsion 
breakers) are commonly used for demulsification in the petroleum-production industry [3]. Emulsions of crude oil and water can be encountered at any stage during drilling, production, transportation and processing of crude oils and in many locations such as in hydrocarbon reservoirs, wellbores, surface facilities, transportation systems and refineries [4].

During oil production and transportation, the water and oil phases are co-produced, and thereby exposed to sufficient mixing energy to form dispersions of water droplets in oil and, conversely, oil droplets in the water [5]. The produced water must be separated from the oil, treated, and disposed properly because sellable crude oil must comply with certain product specifications like the amount of basic sediment and water (BS\&W). If water is left in the crude oil, it will cause high transportation cost, pollution, corrosion, lower the API gravity of oil and thus the price, hydrate formation, water treatment cost and so on [3, 6-11]. Therefore, the emulsion must be treated or prevented as the case may be to have crude oil that meets the minimum qualifications for prospective buyers.

Demulsification can be achieved by three means, namely, mechanical, electrical and chemical. The addition of chemical dispersants to water-in-oil or oil-in-water emulsion is the most widely method used in separating water from oil. Usually, these chemical dispersants (demulsifers) are in anionic, cationic or non-ionic form [2]. Some common examples of modern demulsifier-bases are polyglycol esters, resin derivatives, sulphonates, alkanolamine condensates, oxyalkylated phenols and polyamine derivatives [5]. A great number of demulsifiers have been developed during the past decades; however, nonionic surfactants have been introduced and have found wide application as demulsifiers since in the 1930s. It is well-known that a nonionic surfactant contains two different groups, hydrophilic and hydrophobic. The hydrophilic part commonly includes oxyethylene, hydroxyl, carboxyl, or amine groups, while the hydrophobic part includes mainly, groups of the alkyls and alkylphenols or oxypropylene. According to Oriji and Appah [2], the efficiency of a demulsifier is determined by the nature of the emulsion and the characteristics of the demulsifier.

Chemical demulsifiers are routinely added in the oilfield to effectively settle water-in-crude oil emulsions. Emulsion stability, in turn, is defined by no less than three parameters water drop, oil dryness and interface quality. All these three parameters are direct outputs of the bottle test, and collectively, they provide a more complete picture of emulsion stability as opposed to the use of any singular parameter [11]. Overcoming all of the possible emulsion stabilization mechanisms makes the selection of a suitable demulsifier for breaking the water-in-oil emulsion very challenging [12]. The chemical screening process may involve the combination of several demulsifier chemistries that will have different functions in the emulsion breaker formulation [13].

Today, the chemical demulsification method is by far the most widely used in the oil industry, both from an environmental and technical point of view. Successful chemical formulations (demulsifiers) can drop emulsified water rapidly, provide relatively clean interfaces and produce dry saleable crude [4]. Optimum emulsion breaking with a demulsifier requires: a properly selected chemical for the given emulsion; adequate concentration of chemical; adequate mixing of the chemical in the emulsion; and sufficient retention time in separators to settle water droplets. It may also require the addition of heat, electric grids, and coalesces to facilitate or completely resolve the emulsion.

Several works and experiments have been performed on the demulsification of crude prior to now. These studies focused on testing of many demulsifiers to determine the best candidates for optimization based on dosage. In this connection, this study will examine the potential of industrial based demulsifiers to evaluate the performance of their combined forms as well as the main and interactive effects of two selected demulsifiers' concentration, temperature and time on emulsion separated water volume using design of experiments (DOE) approach.

\subsection{Destabilization of Emulsion}

The treatment of water-in-crude oil emulsions involves seven methods of application such as: heating, gravity settling, electrical and chemical which is widely used in the industry [14]. Thermal method or heat treatment in emulsion breaking is usually based on the overall economic picture of a treating facility. Excess heat is not supplementary when it is more commercial to add chemical or set up electrostatic heat [15]. A good knowledge of petroleum emulsions is necessary for controlling and improving processes at all stages [16]. Several works and experiments have been performed on the demulsification of crude before now. For example, experiments conducted with 121 different demulsifiers resulted in appropriate formulas for optimal demulsifier selection. Chemical demulsification is commonly used to separate water from heavy oils to produce a fluid suitable for pipelining (typically less than 0.5 percent solids and water) [17].

Abouther [18] showed that the mixture of phenol and sulfonic acid was the best chemical additive used to separate water from crude oils. In principle, a complete chemical and physical characterization of both the demulsifier and the emulsion to be separated would allow one to develop a fundamental understanding of the demulsification mechanism and therefore to optimize the demulsifier selection or allow synthesis of tailored demulsifiers for separation of particular emulsions. In practice, this is not yet possible because of the wide range of factors that can affect demulsifier performance. Aside from demulsifier chemistry, factors like oil chemistry, the presence and wettability of solids, oil viscosity and the size distribution of the dispersed water phase can all influence demulsifier effectiveness [19]. As a result, an empirical approach involving the testing of many demulsifiers is undertaken to determine the best candidates for optimization based on dosage. As a first step in developing a fundamental understanding of the relationship between demulsifier chemistry and effectiveness, 121 different demulsifiers and six different produced oil samples were evaluated [18]. 
A correlation between emulsion stability and measured physicochemical parameters showed that the emulsion viscosity, the crude oil viscosity and the content of waxes were the most significant parameters, when comparing observed and calculated stability [14, 20-21]. Chemical companies attempted to formulate good general compounds that will treat as many different crudes as possible. This led to efficiency in the production of demulsifiers by decreasing the best inventory and possible formulation mistakes. A better formulation is found, the number of active ingredients can be decrease and efficiency maintained. Fingas and Fieldhouse [22] carried experiments that suspended bigger droplets in the continuous phase. The chemicals counteracted the emulsifying agent, allowing the dispersed droplets of the emulsion to coalesce into larger drops and settle out of the matrix. It was observed that demulsifiers must be injected into the emulsion, mix thoroughly and made to migrate to all the protective films surrounding all the dispersed fluid. The chemical must also displace or nullify the effect of the emulsifying agent at the interface.

\subsection{How Hydrocarbon is Processed in the Field}

At the Central Processing Facility (CPF) of a field, Crude oil flows from the Well to the inlet manifold via a 4" flowline (Figure 1).

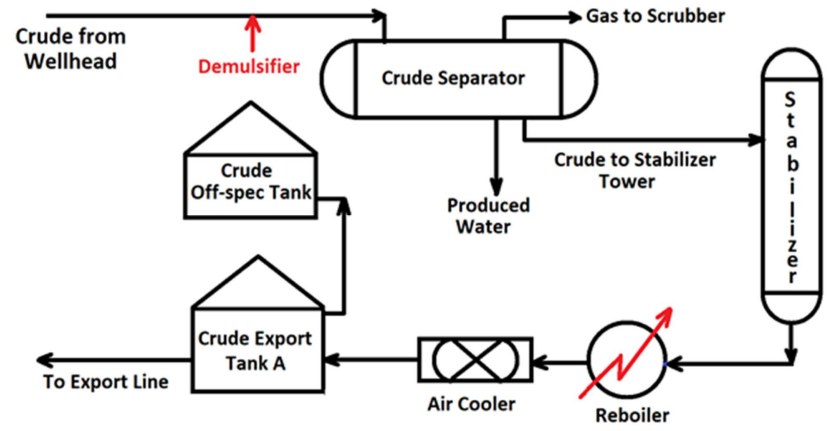

Figure 1. Simplified process flow diagram of crude processing facility [23].

Once the crude oil has reached the inlet manifold, it is injected with a chemical demulsifier designed to break any oil-water emulsion that may be present. The Crude oil then flows into the crude oil separator, which is a horizontal three-phase vessel designed to operate between 160 psig and $220 \mathrm{psig}$, pressures and at $30{ }^{\circ} \mathrm{C}$ temperature which separates the Well fluids into gas, crude oil and water. While the water flows to the produced water separator vessel and the gas is transferred to the overhead compressor unit, the Crude oil from the crude separator is fed to the stabilizer tower unit (STU); which enhances the quality of crude oil obtained by reducing the total vapour pressure (TVP) to 10.5 psia at $40^{\circ} \mathrm{C}$.

The stabilizer re-boiler heats the feed hydrocarbon (crude and condensate) to temperatures between $313^{\circ} \mathrm{C}-399^{\circ} \mathrm{C}$ by using hot oil. The light end from the crude is stripped off by the vapour from the re-boiler that comes in contact with the crude oil/condensate stream while travelling up the column. Stabilized crude oil/condensate from the stabilizer re-boiler is sent to the crude/condensate air cooler, where it is cooled from the re-boiler temperature to approximately $50^{\circ} \mathrm{C}$ before being sent to the storage tank if confirmed to have met specifications.

\section{Materials and Methods}

The crude oil samples were collected from the inlet manifold from the field which is shown in Figure 2. Thereafter the samples were taken to the laboratory for analysis.

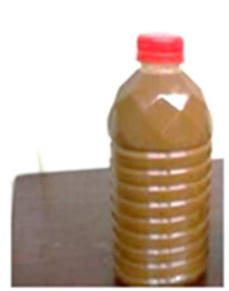

(a)

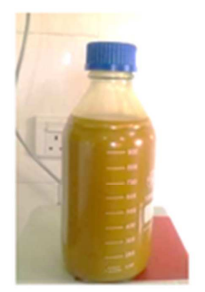

(b)

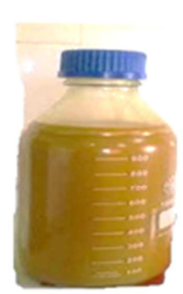

(c)
Figure 2. Well X Crude oil Sample at inlet manifold [24].

At the laboratory, the bottle test $(100 \mathrm{~mL})$ was performed on the collected crude oil sample to determine the basic sediments and water (BS\&W) and the suitable demulsifiers that will break the emulsion. After several tests were conducted with 12 demulsifiers, AnticorQIT007 and DMO7005 performed better than the other demulsifiers in terms of water separation from the crude oil. These demulsifiers were used for the experimental design to examine the potential of combined demulsifiers as well as the effects of the combined demulsifiers' concentration, temperature and time on the separated water volume from the crude oil. The experimental design was the full factorial design with 2 levels (i.e., low and high) and 3 factors, namely, demulsifier concentration (A), temperature (B) and time (C). Thus, the experimental design matrix and the factors threshold are presented in Tables 1 and 2, respectively.

Table 1. Experimental design matrix.

\begin{tabular}{llll}
\hline Concentration & Temperature & Time & Produced Water \\
\hline 0.05 & 60 & 10 & - \\
0.45 & 60 & 10 & - \\
0.05 & 90 & 10 & - \\
0.45 & 90 & 10 & - \\
0.05 & 60 & 60 & - \\
0.45 & 60 & 60 & - \\
0.05 & 90 & 60 & - \\
0.45 & 90 & 60 & - \\
\hline
\end{tabular}

Table 2. Experimental design factor's levels.

\begin{tabular}{lll}
\hline Factors & Level & \\
\hline & Low & High \\
\hline Concentration & 0.05 & 0.45 \\
Temperature & 60 & 90 \\
Time & 10 & 60 \\
\hline
\end{tabular}

Based on the established experimental design matrix (Table 1), the crude oil sample was poured into the test bottle, thereafter, $0.05 \mathrm{~mL}$ (about $50 \mathrm{ppm}$ ) of the AnticorQIT007 
(demulsifier) was added. The test bottle was then placed in the centrifuge for about 4 minutes to obtain a homogenous mixture of the sample with the demulsifier. Afterwards, the test bottle with its content was put in the water bath and the temperature of the bath set at $60^{\circ} \mathrm{C}$. This system was allowed to stay for 10 minutes in the bath; after which the test bottle was removed and the volume of separated water was recorded. This procedure was repeated for other experimental runs as indicated in Table 1 using the demulsifiers (AnticorQIT007 and DMO87005). On the other hand, the designed experiments were performed with the combined demulsifiers at varied ratios as shown in Table 3 . The experimental results obtained were analyzed with MINITAB 17.0 software to establish the main and interactive effects of the demulsifiers (i.e., non-combine and combined) factors: concentration, temperature and time on the responses, that is, separated water volume from the different crude oil samples treatment.

Table 3. Combined Demulsifier Ratios.

\begin{tabular}{llll}
\hline \multicolumn{2}{l}{ Combination Ratio } & & \\
\hline DMO87005 & & AntocorQIT007 & Sample name \\
\hline 1 & 90 & 10 & Sample: $90 / 10$ \\
2 & 80 & 20 & Sample: $80 / 20$ \\
3 & 70 & 30 & Sample: $70 / 30$ \\
4 & 60 & 40 & Sample: $60 / 40$ \\
5 & 50 & 50 & Sample: $50 / 50$ \\
6 & 40 & 60 & Sample: $40 / 60$ \\
7 & 30 & 70 & Sample: $30 / 70$ \\
8 & 20 & 80 & Sample: $20 / 80$ \\
9 & 10 & 90 & Sample: $10 / 90$ \\
\hline
\end{tabular}

\section{Results and Discussion}

\subsection{Pilot test and Experimental Designed Results}

Table 4 presents the separated water volume from the demulsified crude oil samples at varied demulsifiers' concentrations (i.e., $0.2 \mathrm{~mL}, 0.3 \mathrm{~mL}$ and $0.45 \mathrm{~mL}$ ) and temperature $\left(60^{\circ} \mathrm{C}\right.$ and $\left.90^{\circ} \mathrm{C}\right)$ after 60 minutes. From these results in Table 4, it is observed that two demulsifiers: AnticorQIT007 and DMO87005 resulted in more separated water volume than the other demulsifiers. The separated water volume obtained with $0.45 \mathrm{~mL}$ demulsifier concentration at a temperature $90^{\circ} \mathrm{C}$ were $30.0 \mathrm{~mL}$ and $33.0 \mathrm{~mL}$ for AnticorQIT007 and DMO87005, respectively. These results imply that the two demulsifiers were more active than their counterparts to break the stability of the crude oil emulsion. Thus, the performance of these demulsifiers presents their choice for the design of experiments (DOE) based evaluation to determine their combined demulsifying potential as well as the main and interactive effects of these demulsifiers' concentrations, temperature and time on the separated water volume from crude oil emulsion.

Table 4. Demulsification of the crude samples with various demulsifiers at varied concentrations and temperatures.

\begin{tabular}{|c|c|c|c|c|c|c|}
\hline \multirow{2}{*}{ Demulsifiers } & \multicolumn{2}{|c|}{ Separated water vol. at $0.2 \mathrm{~mL}$} & \multicolumn{2}{|c|}{ Separated water vol. at $0.3 \mathrm{~mL}$} & \multicolumn{2}{|c|}{ Separated water vol. at $0.45 \mathrm{~mL}$} \\
\hline & $60^{\circ} \mathrm{C}$ & $90^{\circ} \mathrm{C}$ & $60^{\circ} \mathrm{C}$ & $90^{\circ} \mathrm{C}$ & $60^{\circ} \mathrm{C}$ & $90^{\circ} \mathrm{C}$ \\
\hline Servo CC 8271 & 3.10 & 4.70 & 3.10 & 4.70 & 6.70 & 10.2 \\
\hline Separol NF-36 & 2.40 & 3.60 & 2.40 & 3.60 & 5.40 & 8.10 \\
\hline Baker- Basf V13-312 & 3.10 & 4.90 & 3.10 & 4.90 & 7.70 & 12.0 \\
\hline NACCO-Exxon 006-1442 & 4.80 & 7.20 & 4.80 & 7.20 & 10.2 & 15.4 \\
\hline Tretolite RP 6275 & 3.40 & 5.30 & 3.40 & 5.30 & 6.90 & 10.6 \\
\hline AnticorQIT007 & 18.4 & 24.5 & 22.5 & 28.5 & 27.5 & 30.0 \\
\hline DMO87005 & 20.2 & 26.5 & 23.0 & 30.5 & 25.0 & 33.0 \\
\hline DMO86634 & 13.1 & 12.2 & 13.1 & 20.2 & 15.3 & 28.0 \\
\hline DMO81656 & 13.9 & 12.5 & 13.9 & 20.5 & 17.9 & 25.0 \\
\hline EXP 30 & 10.2 & 16.0 & 10.2 & 16.0 & 20.5 & 22.0 \\
\hline EXP 50 & 11.1 & 18.5 & 11.1 & 18.5 & 22.2 & 27.0 \\
\hline
\end{tabular}

The experimental designed based crude demulsification results with the combined demulsifiers at varied combination ratios are presented in Table 5. From the Table 5, it is observed that the designed experiment results for the combined demulsifiers with a concentration of $0.05 \mathrm{~mL}$ at a temperature of $90^{\circ} \mathrm{C}$ for 60 minutes resulted in separated water volume from the crude emulsion (for the varied demulsifier combination) that was more than that obtained with non-combined demulsifiers (i.e., AnticorQIT007 and DMO87005) (Table 4). This result implied that the combined demulsifier at the mentioned concentration (i.e., $0.05 \mathrm{~mL}$ ) outperformed the non-combined demulsifiers even at their concentration of $0.45 \mathrm{~mL}$. Also, at this $0.05 \mathrm{~mL}$ concentration, a good combination output - separated water volume of $48.30 \mathrm{~mL}$ and $48.20 \mathrm{~mL}$ was obtained with sample $80 / 20$ and sample $40 / 60$, respectively. This performance showed that there was $61.0 \%$ and $46.36 \%$ increase in the separated water volume with these combined demulsifiers when compared with non-combined demulsifiers AnticorQIT007 and DMO87005. Additionally, that the mentioned concentration 
$(0.05 \mathrm{~mL})$ and temperature $\left(90^{\circ} \mathrm{C}\right)$ for 10 minutes, combined demulsifiers: sample $80 / 20$ and sample $40 / 60$ performed $18.33 \%$ and $7.58 \%$ better than the AnticorQIT007 and DMO87005 demulsifiers, respectively.

The results in Table 5 further revealed that the combined demulsifiers at $0.45 \mathrm{~mL}$ concentration for both temperatures of $60^{\circ} \mathrm{C}$ and $90^{\circ} \mathrm{C}$ after 60 minutes resulted in a more increased separated water volume from the crude oil emulsion when compared to the non-combined demulsifiers: AnticorQIT007 and DMO87005 results in Table 4. A closer look at these results (Table 5) indicated that the separated water volume obtained for the various combined demulsifier samples of $0.45 \mathrm{~mL}$ concentration at $90^{\circ} \mathrm{C}$ after 60 minutes were higher than that of $0.45 \mathrm{~mL}$ concentration at $60^{\circ} \mathrm{C}$ after 60 minutes. This observation is attributed to the temperature difference as also asserted by Yi et al. [25]. Regrettably, a variance results were obtained for the combined demulsifier samples of $0.45 \mathrm{~mL}$ concentration at $60^{\circ} \mathrm{C}$ after 10 minutes. In other words, the results - separated water volume obtained at this mentioned demulsification conditions were less than that obtained for non-combined demulsifiers (AnticorQIT007 and DMO87005) of $0.45 \mathrm{~mL}$ concentration at $90^{\circ} \mathrm{C}$ after 60 minutes (Table 4). From the designed experiment results, it is crystal clear that the best demulsification conditions for the combined demulsifier samples are $0.45 \mathrm{ml}$ concentration at a temperature of $90^{\circ} \mathrm{C}$ after 60 minutes. Also, the demulsification conditions (concentration, temperature, time of $0.05 \mathrm{~mL}, 90^{\circ} \mathrm{C}, 60 \mathrm{~min} ; 0.45 \mathrm{~mL}, 90^{\circ} \mathrm{C}, 10 \mathrm{~min} ; 0.45 \mathrm{~mL}$, $60^{\circ} \mathrm{C}, 60 \mathrm{~min}$ and $0.45 \mathrm{~mL}, 90^{\circ} \mathrm{C}, 60 \mathrm{~min}$ ) in Table 5 for the combined demulsifiers will result in a good performance than the non-combined demulsifiers. In sum, the combined demulsifiers give a good potential than the non-combined demulsifiers (AnticorQIT007 and DMO87005), and the potential (separated water volume from the crude emulsion) of the combined demulsifier is dependent on demulsifier combination ratio and demulsification conditions.

Table 5. Experimental designed results for the varied demulsifiers ratio.

\begin{tabular}{|c|c|c|c|c|c|c|c|c|c|c|c|}
\hline \multicolumn{3}{|c|}{ DMO87005 / AnticorQIT007 Ratio } & $90 / 10$ & $80 / 20$ & 70/30 & $60 / 40$ & $50 / 50$ & $40 / 60$ & $30 / 70$ & $20 / 80$ & $10 / 90$ \\
\hline Conc. (mL) & Temp. $\left({ }^{\circ} \mathrm{C}\right)$ & Time (min) & \multicolumn{9}{|c|}{ Produced Water Volume (mL) } \\
\hline 0.05 & 60 & 10 & 18.16 & 15.20 & 15.20 & 12.60 & 14.60 & 12.20 & 16.40 & 12.40 & 10.50 \\
\hline 0.05 & 60 & 60 & 24.10 & 26.20 & 25.20 & 18.50 & 23.60 & 20.50 & 28.40 & 21.20 & 20.80 \\
\hline 0.05 & 90 & 60 & 34.60 & 48.30 & 42.00 & 46.50 & 44.00 & 48.20 & 45.60 & 44.30 & 38.80 \\
\hline 0.05 & 90 & 10 & 25.60 & 35.40 & 28.50 & 30.40 & 18.20 & 35.50 & 30.20 & 30.20 & 20.80 \\
\hline 0.45 & 90 & 10 & 40.20 & 38.50 & 38.30 & 40.20 & 30.40 & 45.00 & 42.60 & 35.80 & 35.20 \\
\hline 0.45 & 60 & 60 & 48.20 & 42.80 & 40.80 & 42.00 & 40.60 & 44.00 & 45.30 & 40.90 & 40.60 \\
\hline 0.45 & 60 & 10 & 20.10 & 20.40 & 20.10 & 14.30 & 20.40 & 16.35 & 20.50 & 28.40 & 15.50 \\
\hline
\end{tabular}

\subsection{Demulsifiers' Parameters Main and Interaction Effects on the Separated Water Volume}

Figures 3 and 4 present the Pareto charts that indicated the main and interaction effects of the demulsifiers' (i.e., AnticorQIT007 and DMO87005) concentration, temperature and time (factors) on the separated water volume (response) as obtained from the DOE results. These results showed that the demulsifiers' concentration is the predominant factor main effect on the separated water volume when compared to temperature and time. The results further revealed that for AnticorQIT007 demulsifier (Figure 3), its concentration dominance on the response - separated water volume was not crucial. This is because the concentration main effect value obtained was not at or across the reference line (i.e., red dash line) on the Pareto chart (Figure 3). For the DMO87005 demulsifier (Figure 4), the demulsifier concentration dominance on the separated water volume was very crucial as this factor main effect value crosses the reference line on the Pareto chart (Figure 4). This observation accounted for the more volume of separated water obtained with the DMO87005 demulsifier than with AnticorQIT007 demulsifier (Table 4). Also, it is noted that the main effect of the time factor on the separated water volume for both demulsifiers is the lowest when compared with concentration and temperature factors.

On the other hand, the interaction effects depict that the demulsifiers' concentration-time effect on the separated water volume was major than other interaction effects (i.e., concentration-temperature, temperature-time and concentration-temperature-time) for both demulsifiers. Again, the dominance of the demulsifiers' concentration-time effect, as well as other interaction effects on the separated water volume, were not crucial as their magnitude obtained did not reach or crosses the reference line on the Pareto charts (Figures 3 and 4). Hence, the main and interaction effects of the demulsifiers' factors on the separated water volume showed that the demulsifier concentration is the most considered factor than temperature and time for the demulsification of crude oil.

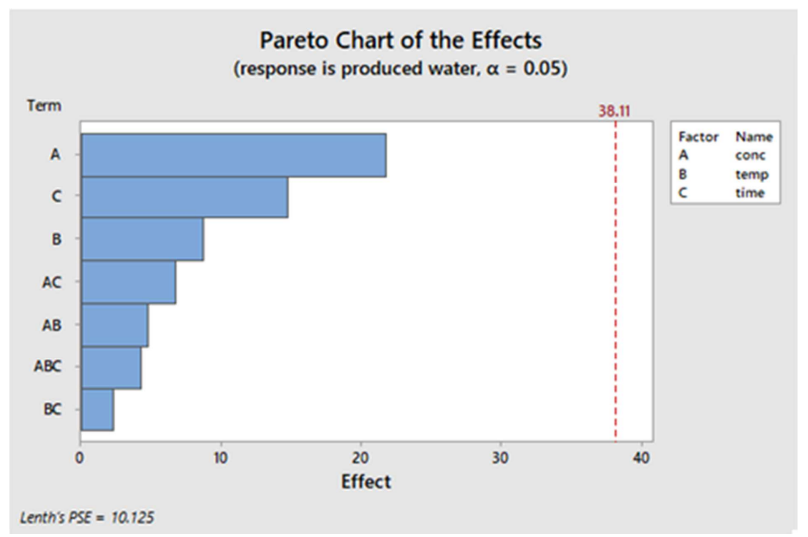

Figure 3. Effect of the varied variable on the emulsion for ANTICORQIT007. 


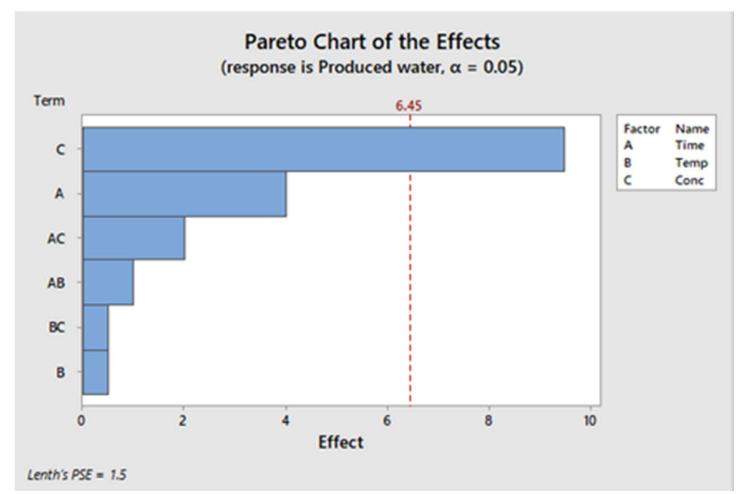

Figure 4. Effect of the varied variable on the emulsion for DMO87005.

Figures 5 through 13 present the main and interaction effects of the combined demulsifier's (as stated in Table 3) factors, namely, concentration, temperature and time, on the separated water volume from the crude oil demulsification. A look at the combined demulsifiers: samples 90/10 and sample $80 / 20$, factors main and interaction effects on the separated water volume from the crude emulsion (Figures 5 and 6) showed that time and concentration were the major factor main effect for sample 90/10 and sample 80/20, respectively. Also, the major factors interaction effect on the response were temperature-time and concentration-time for sample 90/10 and sample $80 / 20$, respectively. These results as presented in the Pareto charts (Figures 5 and 6) showed that the main and interaction effects of the combined demulsifiers (samples 90/10 and sample 80/20) on the response were not critical, as their magnitude were not across the reference line.

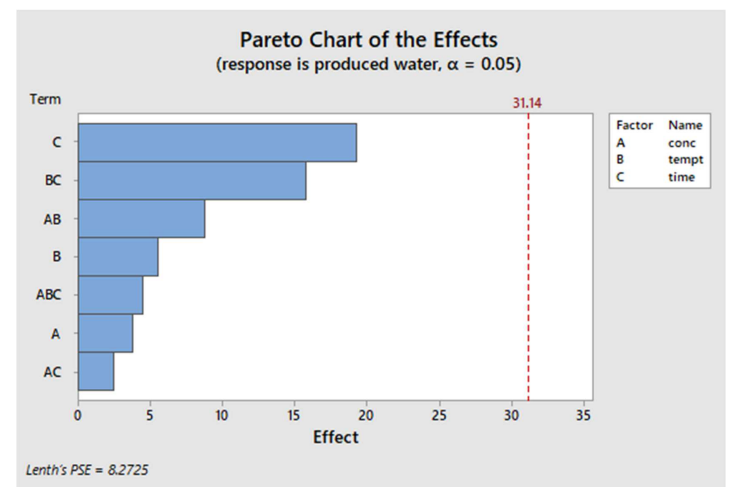

Figure 5. Demulsifier (Sample 90/10) factors' main and interaction effect on response.

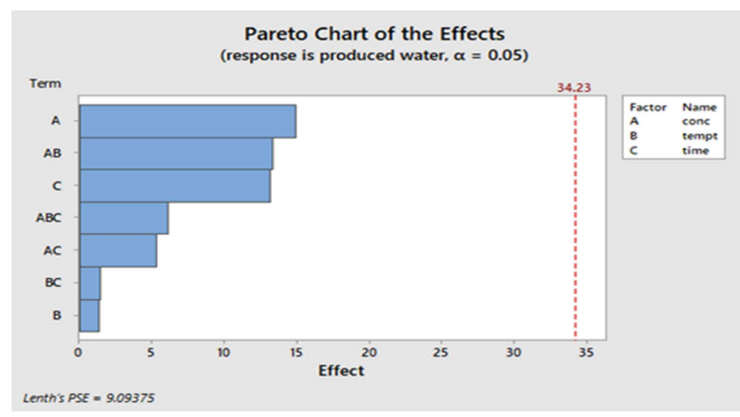

Figure 6. Demulsifier (Sample 80/20) factors' main and interaction effect on response.
Unlike the earlier discussed Figures, Figure 7 presents a variant result where the temperature and time factors are the main effects and concentration-time factor is the major interaction effect on the separated water volume for sample 70/30. However, the dominance of the major main and interaction factors effect on the response was not significant as their magnitudes were less than the reference line on the Pareto chart (Figure 7). From sample $60 / 40$ and sample 50/50 (Figures 8 and 9), the concentration factor was the major main effect on the response. For sample 60/40 (Figure 8), the magnitude of concentration factor as the major main effect was slightly higher than that of the time factor, whereas, for sample 50/50 (Figure 9), the magnitude difference between the concentration factor as the major main effect was higher than that of the time factor. These results further revealed that the prominent interaction effect of the combined demulsifiers (i.e., sample 60/40 and sample 50/50) on the obtained separated water volume was a temperature-time factor. Again, for these combined demulsifiers, the magnitude of the major factors' main and interaction effects on the response - separated water volume is not crucial as their values were less than the reference line on the Pareto charts (Figures 8 and 9).

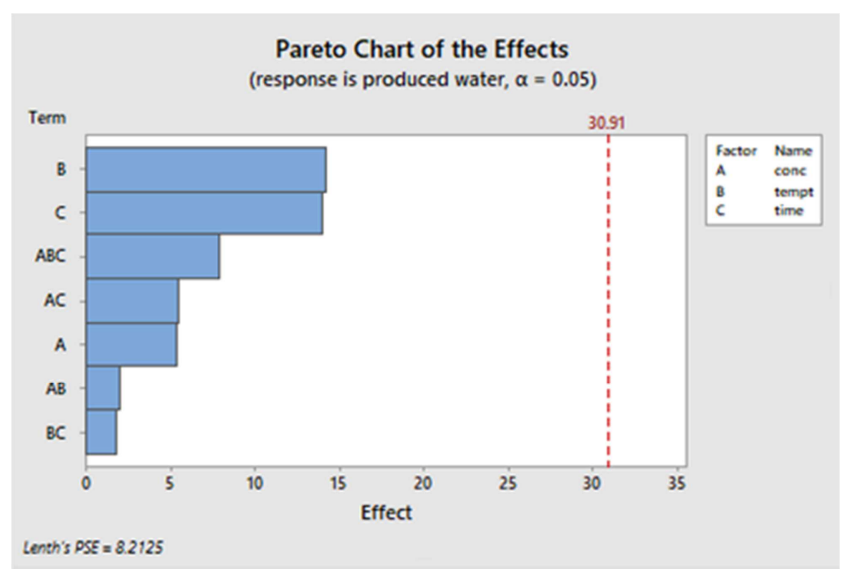

Figure 7. Demulsifier (Sample 70/30) factors' main and interaction effect on response.

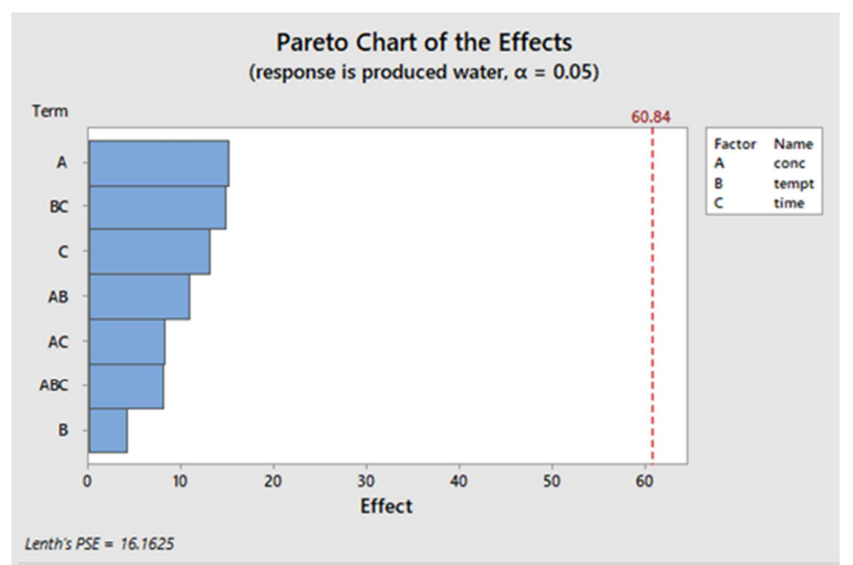

Figure 8. Demulsifier (Sample 60/40) factors' main and interaction effect on response. 


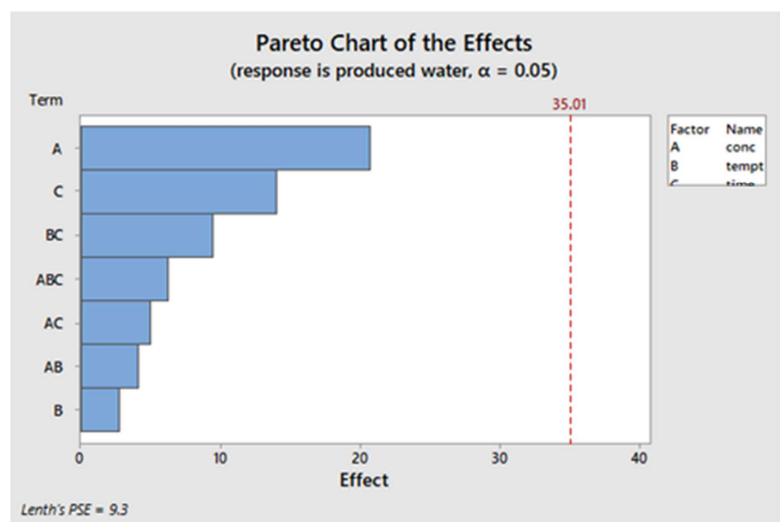

Figure 9. Demulsifier (Sample 50/50) factors' main and interaction effect on response.

Figures 10 and 11 present the main and interaction effect obtained from sample 40/60 and sample 30/70 factors on the separated water volume (response) from the crude emulsion. The result presented for sample 40/60 in Figure 10 indicated that the temperature-time factor was the major interaction effect on the response, and was crucial to the separated water volume. This is because the interaction effect magnitude crosses the reference line on the Pareto chart (Figure 10). Further, the result (Figure 10) showed that the combined demulsifier (sample 40/60) concentration was the factor main effect on the response. However, this factor main effect on the response was not significant as the effect value was far from the reference mark. On the other hand, Figure 11 depicts that for sample 30/70, its concentration factor was the most main effect on the response - separated water volume. This assertion is supported by the concentration factor effect value obtained on the Pareto chart, as its value crosses the reference line. Also, it is observed from the result that the combined demulsifier's concentration-temperature factor was the major interaction effect on the separated water volume. However, the concentration temperature interaction effect was far from the reference line, thus, less significant on the response as observed in Figure 11.

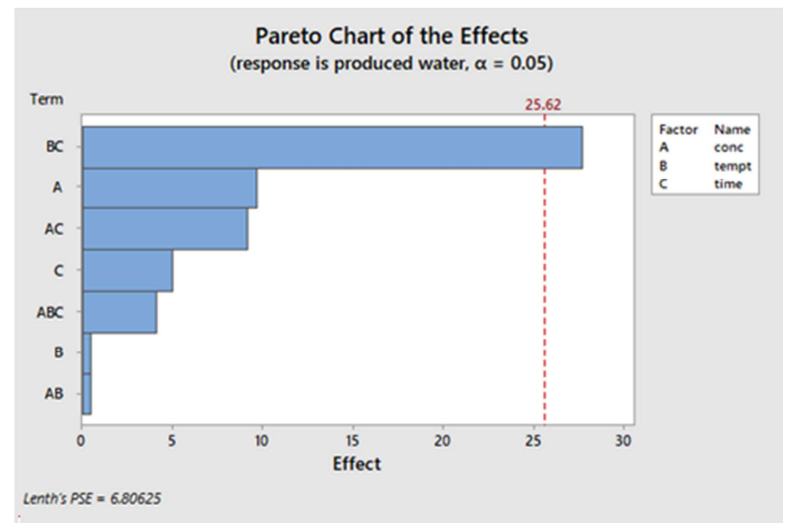

Figure 10. Demulsifier (Sample 40/60) factors' main and interaction effect on response.

Figures 12 and 13 present results of the main and interaction effects of sample 20/80 and sample 10/90 demulsifiers' factors on the response - separated water volume. The result as presented on Pareto chart (Figure 12) for sample 20/80 showed that the major interaction effect is a concentration-temperature factor while the main effect was concentration and time factors on the separated water volume from the crude oil emulsion. Besides, Figure 13 depicts that concentration factor was the main effect and concentration-time factor was the interaction effect on the response (separated water volume) using sample 10/90 for the crude oil demulsification. As noted on the Pareto charts (Figures 12 and 13) the two combined demulsifiers factors' main and interaction effects on the response were not crucial, as these effects' values were less than the reference line value on the charts.

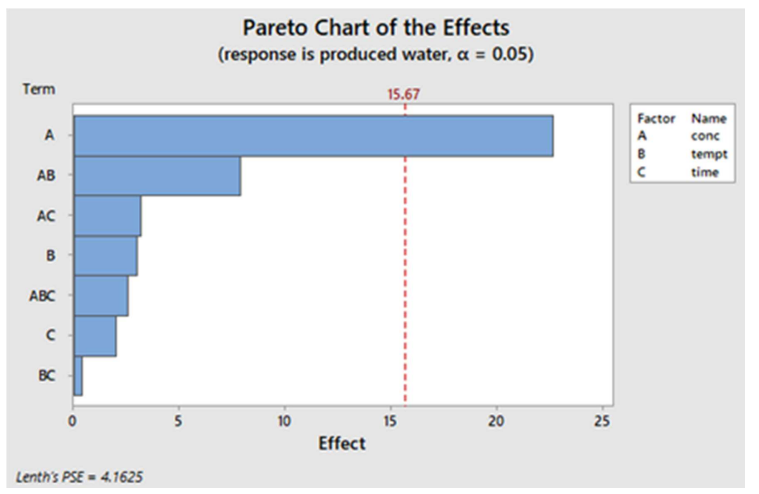

Figure 11. Demulsifier (Sample 30/70) factors' main and interaction effect on response.

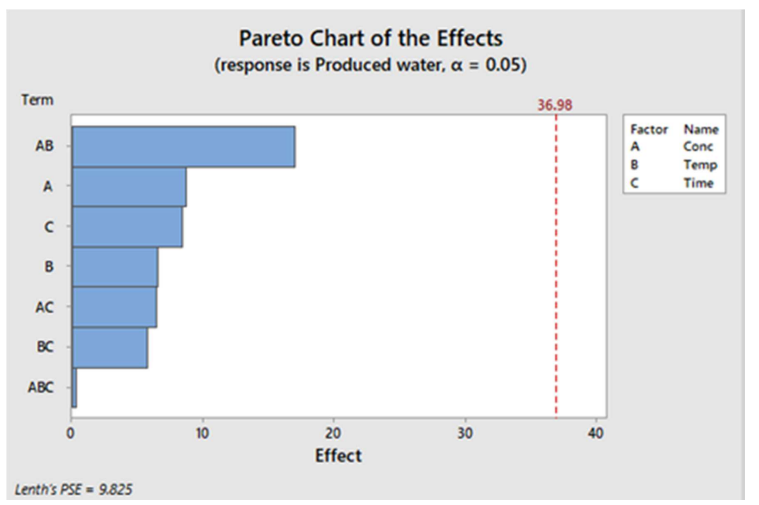

Figure 12. Demulsifier (Sample 20/80) factors 'main and interaction effect on response.

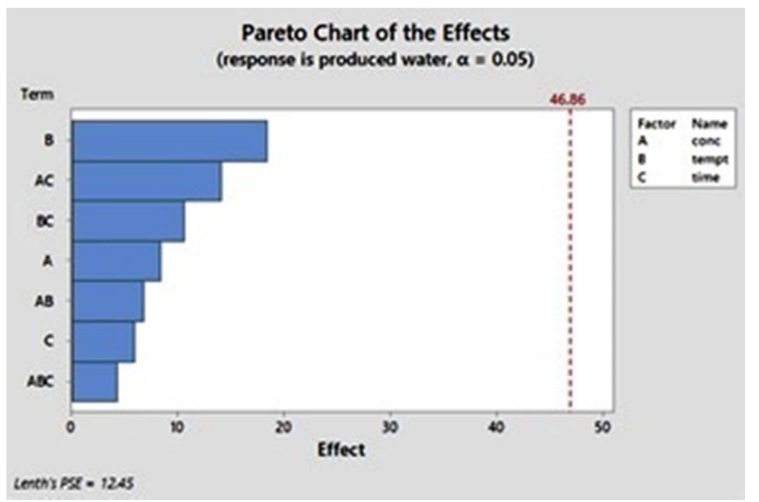

Figure 13. Demulsifier (Sample 10/90) factors 'main and interaction effect on response. 
In summary, the main and interaction effects of the combined demulsifiers factors on the response as presented in Table 6 indicated that the demulsifier concentration is the major main effect while temperature-time is the main interaction effect on the separated water volume from the crude oil samples. Also, the results pointed out that the demulsifiers combination ratio had an effect on the main and interaction effects of the demulsifiers' factors on the response
- separated water volume. The crucial main factor (concentration) effect and interaction factor (temperature-time) effect on the separated water volume was obtained with sample $40 / 60$ and sample $30 / 70$ combination of the demulsifiers. This means that, for the combined demulsifiers, consideration of their demulsification factors, that is, concentration, temperature and time is paramount for the optimum water separation from the crude emulsion.

Table 6. Combined demulsifiers'factors main and interaction effects on separated water volume.

\begin{tabular}{llll}
\hline $\begin{array}{l}\text { Combined } \\
\text { Demulsifier }\end{array}$ & Major Effects on Response & & \\
\cline { 2 - 3 } Crucial Factor(s) on Response & Interaction Effect & None \\
\hline Sample: $90 / 10$ & Time & Temperature-Time & None \\
Sample: $80 / 20$ & Concentration \& Time & Concentration-Temperature & None \\
Sample: $70 / 30$ & Temperature \& Time & Concentration-Time & None \\
Sample: $60 / 40$ & Concentration \& Time & Temperature-Time & None \\
Sample: $50 / 50$ & Concentration \& Time & Temperature-Time & Temperature-Time \\
Sample: $40 / 60$ & Concentration & Temperature-Time & Concentration \\
Sample: $30 / 70$ & Concentration & Concentration-Temperature & None \\
Sample: $20 / 80$ & Concentration \& Time & Concentration-Temperature & None \\
Sample: $10 / 90$ & Temperature & Concentration-Time & \\
\hline
\end{tabular}

\section{Conclusion}

From the experimental designed evaluation of the industrial based demulsifiers in this study, the following conclusions are made:

i. the selected demulsifiers DMO87005 and AnticorQIT007 in a combined form separate more water volume from the crude oil emulsion than the non-combined demulsifiers;

ii. the combined demulsifiers performance (i.e., the volume of water separated from the crude emulsion) is contingent upon the combination ratio of the selected demulsifiers DMO87005 and AnticorQIT007;

iii. the selected (non-combined) demulsifiers (DMO87005 and AnticorQIT007) and the combined demulsifier factors' main effects on the separated water volume from the crude emulsion is concentration, while concentration-time and temperature-time are the factors' interaction effects on separated water volume for selected and combined demulsifiers, respectively; and

iv. for the combined demulsifier, the magnitude of the main and interaction effects of the demulsifier's factors on the separated water volume is affected by the combination ratio of the selected demulsifiers.

\section{Acknowledgements}

The authors wish to thank the management and staff of Frontiers for the access granted to use their Laboratory for the project and the staff members of the Department of Chemical and Petroleum Engineering, Faculty of Engineering, University of Uyo for all the support during this research.

\section{References}

[1] Noik, C., Dalmazzone, L. and Komunjer, L. (2003). Mechanism of crude oil/water interfaced destabilization by silicone demulsifiers. International Journal of Chemistry, 2 (3): 23-45.

[2] Oriji, A. B. and Appah, D. (2012). Suitability of local demulsifier as an emulsion treating agent in oil and gas production. Paper presented at the Society of Petroleum Engineers (SPE) Nigerian Annual International Conference and Exhibition, Abuja, Nigeria, 2-4 August 2012.

[3] Schramm, L. L. (1992). Emulsions: Fundamentals and Applications in the Petroleum Industry. 3rd Edition. John Wiley and Sons, Washington, DC. 230 p.

[4] Sun, T., Zhang, L. Y. and Wang, S. (2002). Influence of demulsifiers of different structures on interfacial dilational properties of an oil-water interface containing surface-active fractions from crude oil. Journal of Colloid Interface Science, 255: 241-247.

[5] Opawale, A. O, Osisanya, A. O, Appah, D. and Otakoro, A. (2011). An Integrated Approach to Selecting and Optimizing Demulsifiers Chemical Injection points using Shearing Energy Analysis: A Justification for Downhole Injection in High Pressured Well. Paper presented at the Offshore Technology Conference, Houston, Texas, 2-5 May 2011.

[6] Auflem, I. H. (2002). Influence of Asphalting Aggregation and Pressure on Crude Oil Emulsion Stability. MSc. Thesis, Norwegian University of Science and Technology. Norway, $53 \mathrm{p}$.

[7] Mohammed, R. A., Bailey, A. I. and Luckham, P. F. (1993). Dewatering of crude oil emulsions: Rheological behaviour of the crude oil water interface. Colloids and Surfaces A: Physicochemical and Engineering Aspects. 80 (2): 223-235.

[8] Sanchez, L. E. and Zakin, J. L. (1994). Transport of viscous crudes as concentrated oil-in-water emulsions. Industrial and Engineering Chemistry Research, 33 (12): 3256-3261. 
[9] Khan, M. R. (1996). Rheological properties of heavy oils and heavy oil emulsions. Energy Sources, 18 (4): 385-391.

[10] Hemmingsen, P. V., Silset, A., Hannisdal, A. E. (2005). Emulsions of heavy crude oils influence of viscosity, temperature and dilution. Journal of Dispersion Science and Technology, 26 (5): 615-627.

[11] Kokal, S. L. (2005). Crude oil emulsions: A state-of-the-art review. Society of Petroleum Engineers Production and Facilities Journal, 20 (1): 5-13.

[12] Abdel-Raouf, M. E. (2012). Factors affecting the stability of crude oil emulsions. Croatia Intech Journal, 23 (2): 1-13.

[13] Poindexter M. K, Chuai S, Marble S. and Marsh S. C. (2006). The Key to predicting emulsion stability: solid content. International oilfield Journal, 3 (2): 1-9.

[14] Aamir, S. A. (1998). De-Emulsification of Different Iraqi Crude Oil Emulsion. MSc. Dissertation, University Baghdad, Iraq.

[15] Rezende, F. C. Rabelo, R. B. and Filho, P. J. C. (2017). The use of Experiments for Development of Flocculating Agents for Treatment of Crude Oil Emulsions. Paper presented at the Offshore Technology Conference Brasil, Rio de Janeiro, Brazil, 24-26 October 2017.

[16] Amadi, N. O. and Ajienka, J. A. (2007). Comparative Evaluation of Environmental Concern in the use of Oilfield Production chemicals. Proceedings of the 1st International Conference and Exhibition on Oilfield Chemistry, University of Port Harcourt, 14-15 June 2007.

[17] Ovuema, A. and Okotie, S. (2015). Emulsion Treatment in the Oil Industry: A Case Study of Oredo Field Crude Oil Emulsion. Paper presented at the Nigeria Annual International Conference and Exhibition, Lagos, 5-7 May 2015.

[18] Abouther, T. H. (2010) Effect of pH and salinity on stability of crude oil water emulsions, Misan Journal for Academic Studies, 9 (17): 2-12.

[19] MacConnachie, C. A., Mikula R. J, Kurucz, L. and Seoular R. J. (1993). Correlation of Demulsifier Performance and Demulsifier Chemistry. Paper Presented at the Petroleum conference of the South Saskatchewan Section, South Saskatchewan, 12-15 June 1993.

[20] Midttun, Ö, Kallevik, H., Sjöblom, J, and Kvalheim, O. (2000). Multivariate screening analysis of water-in-oil emulsions in high external electric field as studied by means of dielectric time domain spectroscopy. Journal of Colloid Interface Science, 227: 262-271.

[21] Einar J. J. and Magnar I. S. (1988). Water-in-Crude oil emulsions from Norwegian continental shelf part formation, characterization and stability correlation, Colloids and Surfaces Journal, 34: 353-370.

[22] Fingas, M. and Fieldhouse, B. (2004). Formation of water in oil emulsions and application to oil spill modeling. Journal of Hazardous Materials 107: 37-50.

[23] Fingas, M., Fieldhouse, B., Bobra, M. and Tennyson, E. (2003). The physics and chemistry of emulsions. Proceedings on workshop on emulsion, marine spill response corporation held at Washington, DC from 12-14 July, 2003, 21 p.

[24] Abatai, M. C (2019). Demulsification of Crude oil emulsion: A case study of a Well in a Crude processing facility in the Niger Delta. MEng. Dissertation, University of Uyo, Uyo, Nigeria.

[25] Yi, M., Huang, J. and Wang L. (2017). Research on crude oil demulsification using the combined method of ultrasound and chemical demulsifier. Journal of Chemistry, 2017: 1-7. https://doi.org/10.1155/2017/914796. 